\title{
FEASIBILITY STUDY OF WIND TURBINE STARTUP SPEED WITH DEAD BAND
}

\author{
YIN, Z. L. ${ }^{1,2}-$ SU, S. ${ }^{1,2, *}-$ BAI, B. ${ }^{1,2}-$ CHEN, Z. ${ }^{1}-$ XIAO, H. ${ }^{1}$ \\ ${ }^{I}$ College of Electrical \& Information Engineering, Changsha University of Science and \\ Technology, Changsha 410004, China \\ (phone: +86-159-7417-2147) \\ ${ }^{2}$ Key Laboratory of Green Energy Technology of Guangdong Province \\ *Corresponding author \\ e-mail:3110315917@qq.com \\ (phone: $+86-159-7417-2147$ ) \\ (Received 22 $2^{\text {nd }}$ Jul 2016; accepted $9^{\text {th }}$ Nov 2016)
}

\begin{abstract}
Wind turbines are usually designed and operated with fix startup speed. It could startup and shutdown repeatedly when the wind fluctuates around the startup speed. The excessive stress induced by frequent startup and shutdown could enhance likelihood of component failure and negatively impact the availability of a wind turbine. The startup speed with dead band is proposed in this article to prevent from frequent startup. 5-year wind data of 15 wind farms are analyzed to evaluate the reduction in the times of startup and potential loss of wind power production using the proposed approach. Numerical simulation suggests that the times of startup could be reduced by half with trivial reduction in potential wind power generation in most of investigated sites once an appropriate dead band is adopted
\end{abstract}

Keywords: wind power; times of startup; mean wind speed; consecutive shutdowns; loss in power production

\section{Introduction}

Wind turbines are hard-to-access structures usually located in remote areas. The wind turbine is a unique power generating system because power train components are subject to highly irregular loading from turbulent wind conditions (Walford, 2006). They are exposed to the risk of component failure due to the extreme and the average wind regimes (Ribrant and Bertling, 2007). The component failure could cause excess maintenance costs and reduce the power generation. It is speculated that the maintenance cost may account for $10 \%$ to $30 \%$ of the total income of wind turbines (Walford, 2006; Ribrant and Bertling, 2007).

Wind turbines operate in the presence of large uncertainties. Many outliers are likely to be generated, particularly during transient operations such as startup and shutdown (Yampikulsakul et al., 2014). For example, frequent operation of circuit breaker during off-grid and grid connection could result in malfunction of circuit breakers notably.

Wind turbines are designed with specific startup speed. Since whether the startup speed could be adjusted are not mentioned in any operation guideline of wind turbine, wind turbines are usually operated with fixed startup speed according to authors' knowledge. Therefore, it could shut down and startup repeatedly when the wind speed fluctuates around its startup speed. The excessive stress and operation of circuit breakers induced by frequent startup and shutdown could enhance likelihood of component failure of a wind turbine.

Startup speed with a dead band is proposed in this article to reduce the times of 
startup. The paper is organized as follows. The concept of startup speed with dead band is introduced in Section II. The wind data utilized for numerical simulation is analyzed in Section III. The feasibility of startup speed with dead band is analyzed in Section IV. Numerical simulation is given in Section V to evaluate performance of startup speed with dead band. Section VI concludes the article.

\section{Startup speed with dead band}

Dead band, an interval of a band where no action occurs, is widely used in controlling applications to prevent oscillation or repeated activation-deactivation cycles. The startup speed with dead band can be described as Fig.l.

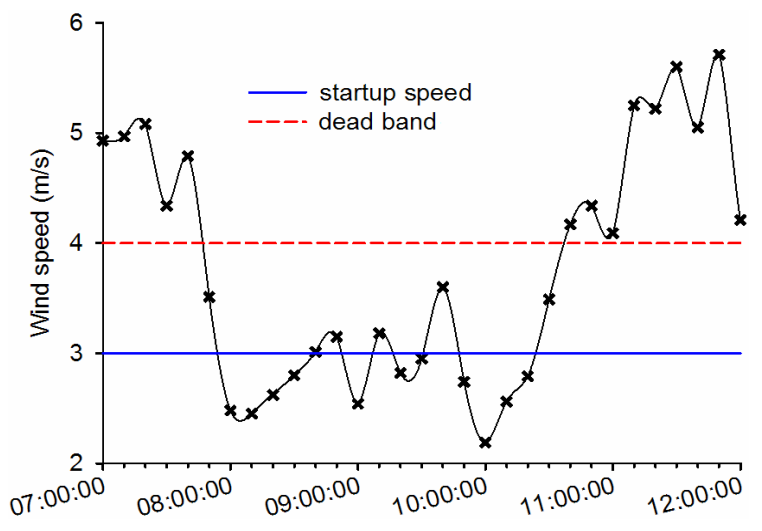

Figure 1. Description of startup speed with dead band

It can be observed that a wind turbine with startup speed of $3.0 \mathrm{~m} / \mathrm{s}$ could startup 4 times from 7:00 to 12:00. It is feasible to add a dead band with lower and upper boundaries of $3.0 \mathrm{~m} / \mathrm{s}$ and $4.0 \mathrm{~m} / \mathrm{s}$ as shown in Fig. I. That is, the wind turbine startup when the wind speed is higher than $4.0 \mathrm{~m} / \mathrm{s}$ and shutdown when the wind speed is lower than $3.0 \mathrm{~m} / \mathrm{s}$. Thereafter, the times of startup could be reduced to 1 as shown in Fig. 1 . Moreover, since wind power is proportional to the cube of wind speed, it is speculated that the slight reduction in wind power generation caused by the dead band could be covered by the potential benefit arise from reduction in times of startup related wear and enhanced availability.

\section{Wind data}

5 years (from Sept. 2, 2003 to Aug. 31, 2008) 10-minute synthetic wind data at a hub height of $85 \mathrm{~m}$ of 15 actual or proposed wind farms in new Zealand (Turner et al., 2009) are investigated in the article. The geographical locations of investigated sites are shown as Fig.2. Of which, STH is the regional identifier for southland and Otago, CTY for Canterbury, CKS for Cook strait, MWT for Manawatu and Wanganui, CNI for Central North Island and Hawkes Bay, and NTH coastal parts of Waikato, Auckland, Coromandel, and Northland (Turner et al., 2009).

Since wind turbines startup and shutdown repeatedly when wind fluctuate around the startup speed, it is speculated that the times of startup could be higher in the sites with lower wind speed than that of sites with higher wind speed. In order to find out whether 
this holds true, the data are analyzed as follows. The times of wind speed surplus and lower than startup speed is counted as times of wind turbine startup and shutdown due to fluctuation of wind speed. The mean wind speed and the times of startup of investigated sites are listed ascending by times of startup as Table 1.

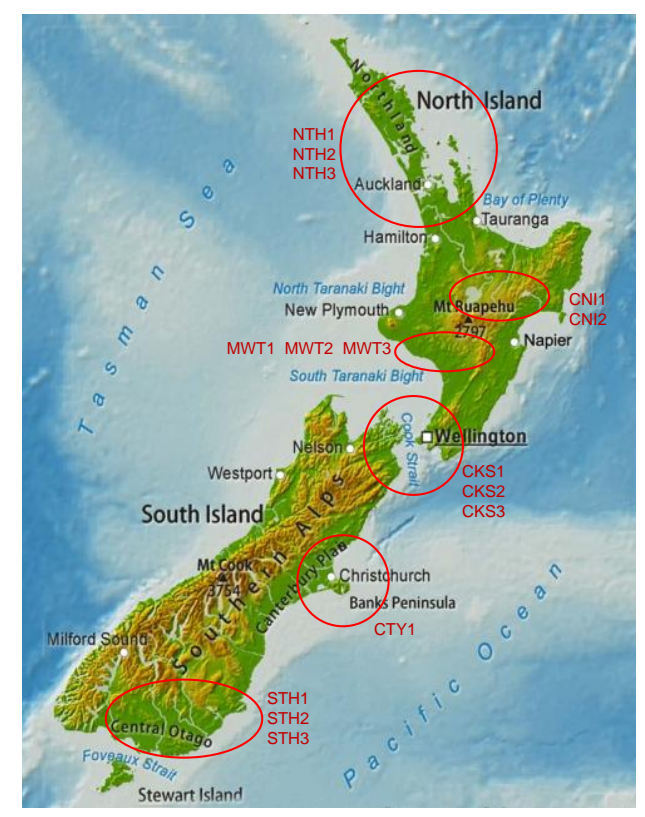

Figure 2. Geographical location of investigated sites

Table 1. Times of startup and mean wind speed in investigated stations

\begin{tabular}{ccc}
\hline Station & Times of startup & Mean wind \\
\hline CKS2 & 2203 & 10.89 \\
MWT1 & 2209 & 10.53 \\
NTH2 & $\mathbf{2 3 0 5}$ & $\mathbf{8 . 3 3}$ \\
MWT3 & 2324 & 9.57 \\
CKS3 & 2327 & 11.3 \\
NTH3 & $\mathbf{2 4 0 4}$ & $\mathbf{8 . 7 3}$ \\
STH3 & 2475 & 11.41 \\
MWT2 & 2762 & 9.91 \\
NTH1 & $\mathbf{2 8 5 8}$ & $\mathbf{8 . 4 5}$ \\
STH2 & 2996 & 9.56 \\
CNI2 & 3010 & 8.49 \\
CKS1 & 3437 & 9.10 \\
CNI1 & 3637 & 9.15 \\
CTY1 & 3890 & 8.28 \\
STH1 & 4763 & 10.08 \\
\hline
\end{tabular}

It can be observed that the time of startup varies notably from sites to sites. The time of startup ranges from 2203 to 4763 and the mean wind speed ranges from $8.28 \mathrm{~m} / \mathrm{s}$ to $11.41 \mathrm{~m} / \mathrm{s}$. However, there is no obvious relation between the mean wind speed and the times of startup. For example, the STH1 with a higher mean wind speed of $10.08 \mathrm{~m} / \mathrm{s}$ has the highest times of startup of 4763. On the contrary, NTH1, NTH2, and NTH3 with lower mean wind speed have the lower times of startup, too. 
Since the local topography has a notable impact on the regional wind characteristics (National Renewable Energy Laboratory, 1997; Ashcroft, 1994), it is speculated that the topography could play an important role in the times of startup. The sites over the open sea and flat terrain tend to have stable wind condition. Therefore, the fluctuation in wind speed and the times of startup and shutdown of wind turbines could be lower. On the contrary, the sites over complex terrain with larger roughness tend to have higher turbulence and gust. The wind turbines could startup and shutdown more frequently under such unstable wind condition.

According to geographic map of New Zealand as shown in Fig.2, the sites NTH1, NTH2, and NTH3 locate in open plain with flat terrain. Therefore, both the times of startup and mean wind speed in these sites are lower than that of other sites. Moreover, STH1, the site with highest times of startup, has a mean wind speed of $10.08 \mathrm{~m} / \mathrm{s}$, which is higher than majority of investigated sites. However, since accurate geographic location information of these sites is not accessible, we cannot identify the accurate factors that determine times of startup in a wind farm with investigated data.

\section{Feasibility of startup speed with dead band}

The dead band has gotten extensive application in control engineering, such as pitch and yaw control of wind turbine (Anthonis et al., 2007, Wu et al., 2012), tap change of transformer (Choi et al., 2009), etc. Usually, the purpose is to prevent oscillation or repeated activation-deactivation cycles and avoid unnecessary control.

Undoubtedly, unnecessary startup and shutdown of wind turbine could be prevented by dead band at large. However, it should be pointed out that the reduction in times of startup and shutdown of wind turbine is achieved at the cost of reduction in wind power generation, which should be evaluated too.

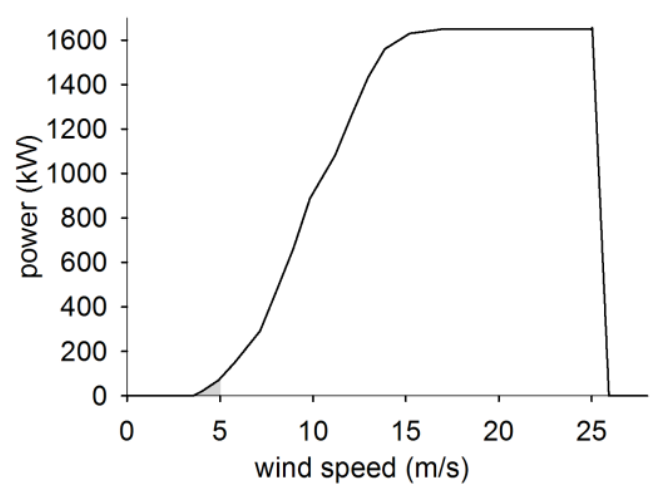

Figure 3. Wind power curve of Vestas 66-1650

The Vestas 66-1650 turbine (Power curve of Vestas, 2008) with a startup speed of 3.0 $\mathrm{m} / \mathrm{s}$ is utilized in this study. The wind power curve is plotted as Fig.3. Since wind power that can be exploited is proportional to the cube of wind speed, the power production is rather low below $5.0 \mathrm{~m} / \mathrm{s}$ as shown in shaded area of wind power curve. Therefore, it seems reasonable to establish a dead band below $5.0 \mathrm{~m} / \mathrm{s}$ to avoid unnecessary startup and shutdown at the cost of slight reduction in wind power generation.

The potential effect of dead band should be evaluated. Since wind is caused by differences in atmospheric pressure, it is widely accepted that there is inherent temporal 
continuity in the wind speed (National Renewable Energy Laboratory, 1997). Therefore, it is reasonable to speculate that once the wind speed fluctuates over startup speed, the likelihood that a wind turbine to shutdown in the following time span is high. The intervals between consecutive startup and shutdown are calculated and their cumulative distribution functions are plotted as Fig.4.

The horizontal plot denotes interval between consecutive startup and shutdowns. The vertical plot denotes the likelihood of wind lower than startup speed $(3.0 \mathrm{~m} / \mathrm{s}$ in this article) within given time span.
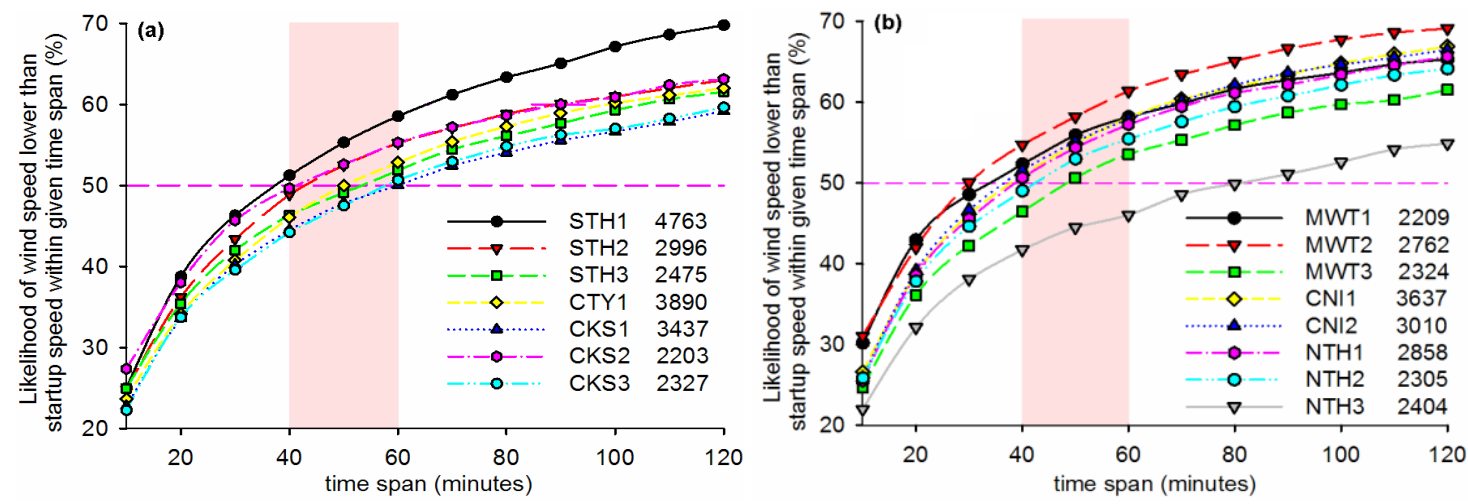

Figure 4. CDF of intervals between consecutive shutdowns

It can be observed from Fig.4 that once a Vestas 66-1650 turbine startup, the likelihood that it re-shutdown within 10 minutes is around $20 \%$ to $30 \%$ in all investigated sites. The likelihood that it re-shutdown within 40 to 60 minutes is over $50 \%$ in most of investigated sites as shown in shaded area of Fig.4. Therefore, unnecessary startup and shutdown could be prevented substantially once appropriate approach is adopted.

It should be pointed out that the curve of NTH3 escalates much slower than that of other sites. When wind turbine startup, the likelihood that it shut down within 80 minutes is around $50 \%$ in the NTH3, which is $20 \mathrm{~min}$ more than that of other sites. The difference might be attributed to the stable wind condition over open terrain of the site.

\section{Numerical simulation}

\section{Reduction in the times of startup}

Appropriate configuration of dead band plays a key role to the reduction of times of startup. Startup speed of Vestas $66-1650,3.0 \mathrm{~m} / \mathrm{s}$, is used as lower boundary of dead band. $3.1 \mathrm{~m} / \mathrm{s}, 3.2 \mathrm{~m} / \mathrm{s}$ to $5.0 \mathrm{~m} / \mathrm{s}$ with a step of $0.1 \mathrm{~m} / \mathrm{s}$ are used as upper boundary of the dead band. The times of startup associate with various upper boundaries are calculated with wind data and plotted as Fig.5. The detailed information is listed as Table 2.

- It can be observed there are unambiguous decline trends in all sites. The times of startup decline notably with higher upper boundary adopted.

- The decline ratio of times of startup fall off with higher upper boundary adopted. The decline ratio with an upper boundary over $4.0 \mathrm{~m} / \mathrm{s}$ is notably milder as compared to those below $4.0 \mathrm{~m} / \mathrm{s}$ in all sites. 
- The decline ratios of majority of sites with less times of startup, such as CKS3 (2327), NTH3 (2404), STH3 (2475), and MWT3 (2324), are milder than that of other sites. The times of startup with an upper boundary of $4.0 \mathrm{~m} / \mathrm{s}$ in these sites are $68 \%$, $55 \%, 53 \%$, and $56 \%$ of original times of startup. It is speculated that the mild declining could be caused by the stable wind condition of these sites.

- The times of startup in majority of stations, except CKS1 and above 4 sites, decline to below $50 \%$ of original number with an upper boundary of $4.0 \mathrm{~m} / \mathrm{s}$.

- The largest reduction (2176) occurs in STH1 while the smallest reduction (729) occurs in CKS3.

Table 2. Time of startup in stations with various upper boundaries of dead band

\begin{tabular}{|c|c|c|c|c|c|c|c|c|c|c|c|c|c|c|c|}
\hline $\begin{array}{c}\text { boundary } \\
(\mathbf{m} / \mathbf{s})\end{array}$ & STH1 & STH2 & STH3 & CTY1 & CKS1 & CKS2 & CKS3 & MWT1 & MWT & $\mathbf{M W}$ & CNI1 & CNI2 & NTH1 & NTH2 & NTH3 \\
\hline 3.0 & 4763 & 2996 & 2475 & 3890 & 3437 & 2203 & 2327 & 2209 & 2762 & 2324 & 3637 & 3010 & 2858 & 2305 & 2404 \\
\hline .1 & 4357 & 730 & 2264 & 3492 & & & 2211 & 1966 & 2483 & 2152 & 3273 & & & & 2200 \\
\hline 3.2 & 4055 & 546 & 2117 & 3223 & 2996 & 1772 & 2123 & 1770 & 2254 & 2007 & 2996 & 2459 & 2334 & & 2028 \\
\hline .3 & 3777 & 358 & 1974 & 3003 & 2822 & & 2031 & 1609 & 2062 & 1881 & 2762 & & 2141 & 1731 & 1906 \\
\hline & 3532 & 185 & 1838 & 2799 & 2659 & 1508 & 1960 & 1463 & 1874 & 1766 & 2536 & & & 1591 & 1789 \\
\hline & 330 & & & & & & & & & & & & & 1476 & 1701 \\
\hline & 128 & & & & & & & & & & & & & & \\
\hline & 2967 & & & 2295 & & 1237 & & & 1488 & & & & & 1269 & 1532 \\
\hline & & & & & & & & & & & & & & & \\
\hline & 2709 & 1644 & & 2081 & 2125 & 1116 & 16 & 1089 & 1310 & & 18 & & & 13 & 1398 \\
\hline & 57 & & & 1994 & 2044 & 1067 & 15 & & 1246 & 13 & 1772 & & & & 1329 \\
\hline & & 1509 & & 1930 & & & & & 1196 & & 1701 & & & & 1283 \\
\hline & 394 & & 1267 & & & & & & & 1222 & & & & 983 & 1233 \\
\hline & 301 & & 1232 & & & & & & & & & & & & 1189 \\
\hline & 2221 & 1344 & 1189 & 1751 & 1826 & 918 & 1418 & & 1055 & 1130 & 1514 & 1186 & & 929 & 1158 \\
\hline & 2140 & & & 1688 & 1774 & 878 & & & 1010 & 1094 & & & & 907 & 1124 \\
\hline & & & & & & & & & & & & & & & \\
\hline & 1981 & & 1106 & 1590 & 1692 & 834 & 1323 & 830 & 933 & 1030 & 1367 & 1051 & 1012 & 844 & 1075 \\
\hline & 1903 & & & & & & & & & & & 1020 & & 821 & 1053 \\
\hline 4.9 & & & & & & 809 & & 796 & & & & & & 794 & 1036 \\
\hline 5.0 & 1777 & 1136 & 1035 & 1471 & 1592 & 794 & 1244 & 787 & 839 & 957 & 1249 & 961 & 932 & 772 & 1015 \\
\hline
\end{tabular}
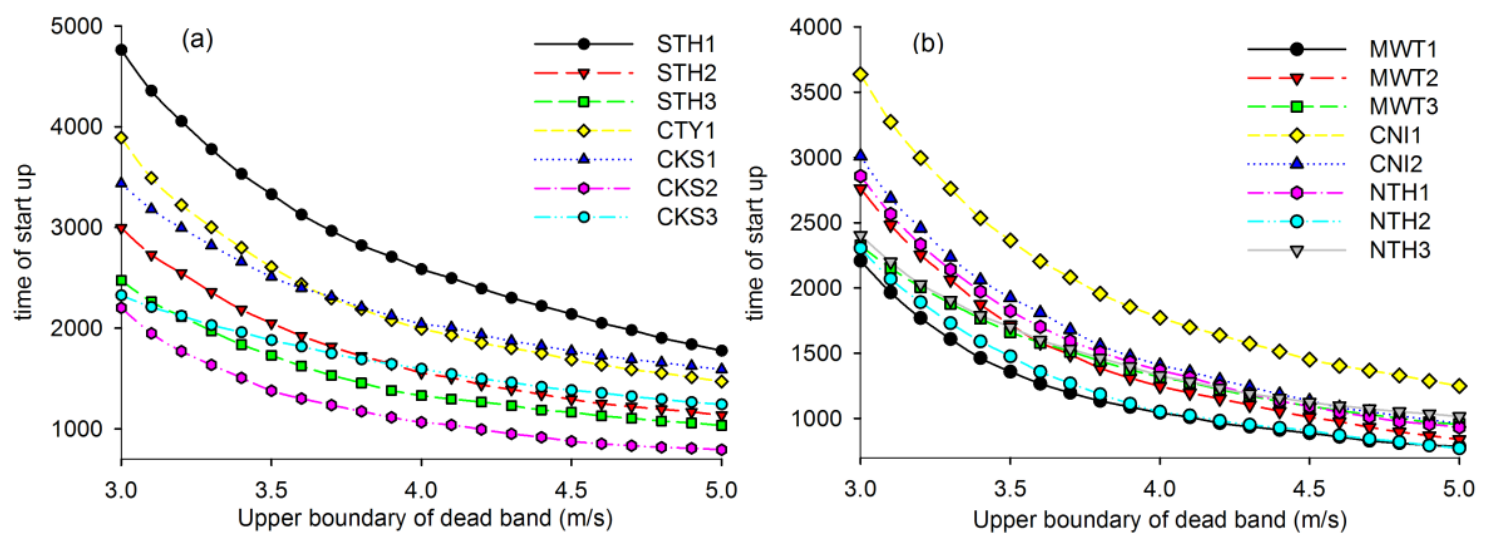

Figure 5. Time of startup in stations with various dead band boundaries

\section{Reduction in the wind power generation}

The times of startup is reduced at the cost of reduction in wind power generation. The reduction in potential wind power generation associate with various upper boundaries are calculated and plotted as Fig. 6 . The reduction below $4.0 \mathrm{~m} / \mathrm{s}$ is enlarged and plotted in shaded area. The detailed information is listed as Table 3. 
- Since the cut-in speed of Vestas $66-1650$ is $3.5 \mathrm{~m} / \mathrm{s}$, there is only trivial loss in wind power generation below the cut-in speed. Consequently, loss in wind power generation is slim with upper boundary of $3.5 \mathrm{~m} / \mathrm{s}$.

- It can be observed that the loss curves of wind power generation escalate slowly below $4.0 \mathrm{~m} / \mathrm{s}$. The loss in wind power generation range from $1545 \mathrm{kWh}$ to 4308 $\mathrm{kWh}$ with upper boundary of $4.0 \mathrm{~m} / \mathrm{s}$ during the whole 5 years.

- The loss in wind power generation escalates rapidly when upper boundary of dead band over $4.0 \mathrm{~m} / \mathrm{s}$ adopted. The loss in wind power generation range from 17834 $\mathrm{kWh}$ to $48492 \mathrm{kWh}$ with upper boundary of $5.0 \mathrm{~m} / \mathrm{s}$, which is 10 times higher than that of $4.0 \mathrm{~m} / \mathrm{s}$.
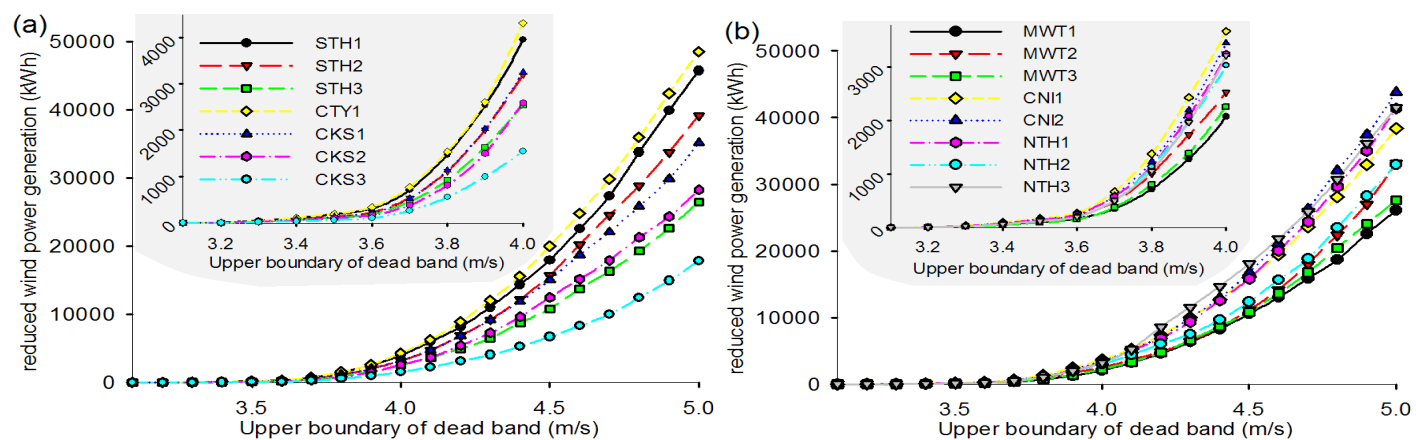

Figure 6. Loss in wind power generation associated with various upper boundaries of dead band

Table 3. Loss in power production with various dead band boundaries

\begin{tabular}{crrrrrrrrrrrrrrrr}
\hline $\begin{array}{c}\text { boundary } \\
(\mathbf{m} / \mathbf{s})\end{array}$ & STH1 & STH2 & STH3 & CTY1 & CKS1 & CKS2 & CKS3 & MWT1 MWT2 MWT3 & CNI1 & CNI2 & NTH1 & NTH2 & NTH3 \\
\hline 3.1 & 0 & 0 & 0 & 0 & 0 & 0 & 0 & 0 & 0 & 0 & 0 & 0 & 0 & 0 & 0 \\
3.2 & 8 & 5 & 5 & 8 & 5 & 4 & 2 & 4 & 6 & 4 & 7 & 6 & 6 & 4 & 4 \\
3.3 & 42 & 27 & 23 & 41 & 29 & 22 & 13 & 23 & 29 & 20 & 36 & 34 & 33 & 26 & 24 \\
3.4 & 100 & 68 & 61 & 106 & 71 & 54 & 33 & 58 & 70 & 48 & 94 & 80 & 79 & 65 & 60 \\
3.5 & 180 & 131 & 110 & 195 & 131 & 101 & 61 & 98 & 132 & 91 & 171 & 150 & 145 & 123 & 117 \\
3.6 & 303 & 222 & 187 & 335 & 213 & 165 & 99 & 165 & 216 & 151 & 275 & 239 & 244 & 210 & 195 \\
3.7 & 699 & 536 & 457 & 770 & 518 & 380 & 264 & 349 & 481 & 374 & 669 & 598 & 581 & 503 & 498 \\
3.8 & 1473 & 1110 & 919 & 1537 & 1133 & 811 & 553 & 713 & 1001 & 798 & 1376 & 1227 & 1138 & 1137 & 1053 \\
3.9 & 2540 & 2007 & 1636 & 2607 & 2026 & 1495 & 992 & 1278 & 1725 & 1390 & 2425 & 2184 & 2082 & 1971 & 1967 \\
4.0 & 3957 & 3194 & 2539 & 4309 & 3250 & 2589 & 1545 & 2066 & 2518 & 2254 & 3662 & 3439 & 3234 & 3023 & 3204 \\
4.1 & 5950 & 4718 & 3657 & 6247 & 4766 & 3702 & 2269 & 3242 & 3650 & 3345 & 5277 & 5063 & 5005 & 4407 & 5231 \\
4.2 & 8138 & 6871 & 4919 & 8921 & 6817 & 5391 & 3137 & 4597 & 4844 & 4738 & 7383 & 7204 & 6898 & 6020 & 8589 \\
4.3 & 11020 & 9186 & 6459 & 12022 & 9212 & 7259 & 4041 & 6310 & 6462 & 6599 & 10029 & 9940 & 9386 & 7533 & 11569 \\
4.4 & 14350 & 12208 & 8713 & 15594 & 11864 & 9605 & 5261 & 8256 & 8543 & 8675 & 12704 & 12964 & 12576 & 9672 & 14684 \\
4.5 & 17930 & 15702 & 10786 & 19988 & 15056 & 12475 & 6690 & 10559 & 11131 & 10847 & 16069 & 16782 & 15841 & 12385 & 18091 \\
4.6 & 22506 & 20216 & 13727 & 24761 & 18679 & 15161 & 8312 & 12977 & 14184 & 13647 & 19410 & 21140 & 20045 & 15626 & 21822 \\
4.7 & 27316 & 24531 & 16296 & 29832 & 22062 & 17910 & 10005 & 15862 & 18017 & 16773 & 23605 & 26317 & 24370 & 18848 & 25925 \\
4.8 & 33750 & 28854 & 19283 & 35932 & 25802 & 21272 & 12414 & 18671 & 22393 & 20440 & 28111 & 32071 & 29671 & 23465 & 30732 \\
4.9 & 39888 & 33748 & 22622 & 42368 & 29836 & 24306 & 14921 & 22555 & 27029 & 24088 & 32983 & 37422 & 35020 & 28254 & 36146 \\
5.0 & 45697 & 39154 & 26452 & 48492 & 35162 & 28212 & 17834 & 26052 & 33160 & 27578 & 38333 & 43832 & 41366 & 32931 & 41484 \\
\hline
\end{tabular}

\section{Selection of upper boundary of dead band}

Since reduction in times of startup is achieved at the cost of loss of wind power generation, selection of boundary of dead band should be determined based on tradeoff between the potential benefit and the cost. The cost induced by reduction in wind power generation could be roughly evaluated with historical wind data. The benefit led by 
reduction in startup should be evaluated with enhanced reliability and availability. Since reliability and availability of wind turbines are determined by a series factors, it is not feasible to quantify the benefit led by reduction in startup \& shutdown of wind turbines. Therefore, it is acceptable to select an affordable cost as the boundary of dead band for the potential benefit of uncertainty.

It can be observed from Fig. 6 and Table 3 that the loss in wind power generation range from $1545 \mathrm{kWh}$ to $4308 \mathrm{kWh}$ with a boundary of $4.0 \mathrm{~m} / \mathrm{s}$ during the whole 5 years. The cost is $\$ 77.25$ to $\$ 215.4$ according to a power purchase agreement of $\$ 50 / \mathrm{MWh}$. It is trivial as compared to reduction of times of startup \& shutdown by half (ranging from 729 to 2176) in majority of sites. Therefore, $4.0 \mathrm{~m} / \mathrm{s}$ could be an acceptable candidate for upper boundary of dead band.

Since the investigated sites are of diversified wind condition, ultimate selection of the dead band depends on wind condition of the sites. In order to provide an integrate knowledge of the cost and benefit of dead band, the loss in wind power generation is divided by the reduction in times of startup \& shutdown and listed as Table 4 . The data are plotted as Fig.7.
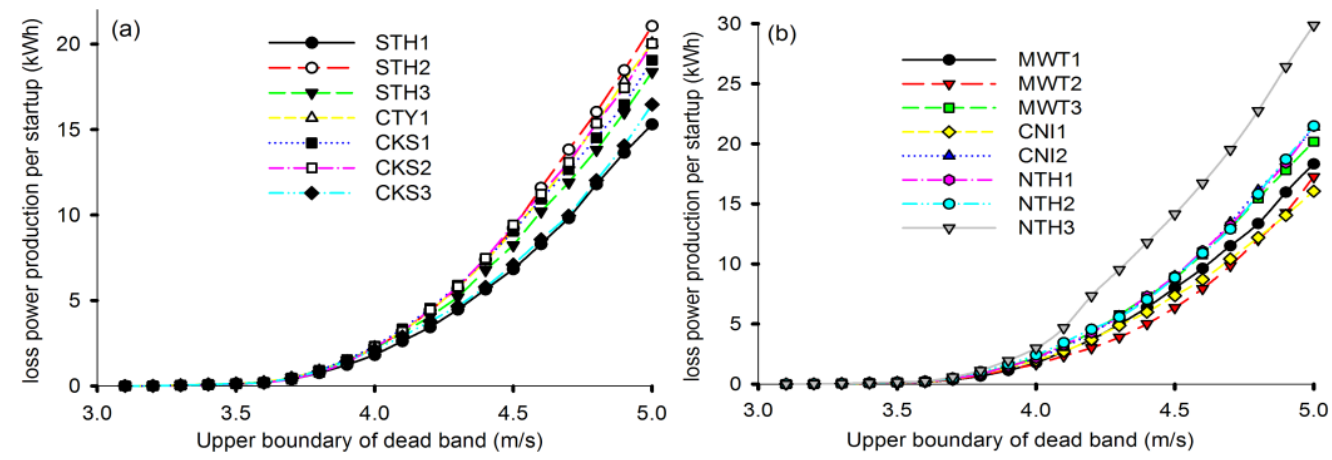

Figure 7. Loss in wind power generation associated with various upper boundaries of dead band

Table 4. Loss in power production per reduction in time of startup

\begin{tabular}{|c|c|c|c|c|c|c|c|c|c|c|c|c|c|c|}
\hline & STH1 & STH3 & CTY1 & CKS1 & CKS2 & CKS3 & MWT1 & MWT2 & MWT3 & CNI1 & CNI2 & NTH1 & NTH2 & NTH3 \\
\hline 3.1 & 0 & 0 & 0 & 0 & 0 & 0 & 0 & 0 & 0 & 0 & 0 & 0 & 0 & 0 \\
\hline 3.2 & 0.011 & 0.014 & 0.012 & 0.011 & 0.009 & 0.010 & 0.009 & 0.012 & 0.013 & 0.011 & 0.011 & 0.012 & 0.010 & 0.011 \\
\hline 3.3 & 0.043 & 0.046 & 0.046 & 0.047 & 0.039 & 0.044 & 0.038 & 0.041 & 0.045 & 0.041 & 0.044 & 0.046 & 0.045 & 0.048 \\
\hline 3.4 & 0.081 & 0.096 & 0.097 & 0.091 & 0.078 & 0.090 & 0.078 & 0.079 & 0.086 & 0.085 & 0.084 & 0.089 & 0.091 & 0.098 \\
\hline 3.5 & 0.126 & 0.148 & 0.152 & 0.141 & 0.123 & 0.137 & 0.115 & 0.126 & 0.137 & 0.134 & 0.138 & 0.140 & 0.148 & 0.166 \\
\hline 3.6 & 0.185 & 0.220 & 0.231 & 0.205 & 0.183 & 0.195 & 0.175 & 0.183 & 0.203 & 0.192 & 0.199 & 0.211 & 0.222 & 0.243 \\
\hline 3.7 & 0.389 & 0.485 & 0.483 & 0.461 & 0.393 & 0.458 & 0.345 & 0.377 & 0.462 & 0.430 & 0.450 & 0.460 & 0.486 & 0.571 \\
\hline 3.8 & 0.759 & 0.903 & 0.904 & 0.923 & 0.789 & 0.870 & 0.664 & 0.728 & 0.903 & 0.819 & 0.847 & 0.844 & 1.016 & 1.119 \\
\hline 3.9 & 1.237 & 1.498 & 1.441 & 1.544 & 1.375 & 1.455 & 1.141 & 1.188 & 1.463 & 1.362 & 1.426 & 1.461 & 1.654 & 1.955 \\
\hline 4.0 & 1.818 & 2.221 & 2.273 & 2.333 & 2.279 & 2.119 & 1.773 & 1.661 & 2.241 & 1.964 & 2.148 & 2.171 & 2.415 & 2.981 \\
\hline 4.1 & 2.626 & 3.104 & 3.187 & 3.335 & 3.183 & 2.902 & 2.704 & 2.331 & 3.189 & 2.726 & 3.063 & 3.242 & 3.440 & 4.666 \\
\hline 4.2 & 3.435 & 4.072 & 4.382 & 4.548 & 4.466 & 3.784 & & & 4.300 & 3.693 & 4.206 & 4.285 & 4.554 & 7.335 \\
\hline 4.3 & 4.476 & 5.196 & 5.755 & 5.894 & 5.803 & 4.666 & 4.965 & 3.895 & 5.738 & 4.861 & 5.622 & 5.624 & 5.572 & 9.522 \\
\hline 4.4 & 5.645 & 6.775 & 7.290 & 7.364 & 7.475 & 5.788 & 6.370 & 5.005 & 7.266 & 5.984 & 7.108 & 7.295 & 7.029 & 11.785 \\
\hline 4.5 & 6.836 & 8.234 & 9.077 & 9.054 & 9.415 & 7.102 & 7.993 & 6.353 & 8.819 & 7.351 & 8.955 & 8.970 & 8.859 & 14.134 \\
\hline 4.6 & 8.299 & 10.206 & 10.995 & 10.936 & 11.230 & 8.569 & 9.620 & 7.937 & 10.797 & 8.696 & 10.976 & 11.081 & 10.897 & 16.709 \\
\hline 4.7 & 9.819 & 11.904 & 12.970 & 12.643 & 13.083 & 9.9651 & 11.503 & 9.8507 & 12.962 & 10.399 & 13.434 & 13.202 & 12.901 & 19.507 \\
\hline 4.8 & 11.801 & 13.813 & 15.388 & 14.512 & 15.359 & 12.029 & 13.356 & 12.007 & 15.450 & 12.185 & 16.116 & 15.774 & 15.812 & 22.748 \\
\hline 4.9 & 13.646 & 15.987 & 17.832 & 16.466 & 17.436 & 14.063 & 15.963 & 14.271 & 17.803 & 14.041 & 18.526 & 18.412 & 18.699 & 26.423 \\
\hline 5.0 & 15.304 & 18.369 & 20.046 & 19.058 & 20.023 & 16.467 & 18.321 & 17.244 & 20.174 & 16.052 & 21.392 & 21.478 & 21.481 & 29.866 \\
\hline
\end{tabular}


It can be observed that there is slim deviation in loss of power production per startup below $4.0 \mathrm{~m} / \mathrm{s}$ since there is only trivial loss in wind power generation. Losses of power production per startup range between $1.6 \mathrm{kWh}$ to $3.0 \mathrm{kWh}$ with a boundary of $4.0 \mathrm{~m} / \mathrm{s}$. The reduction in power production per startup escalated rapidly over $4.0 \mathrm{~m} / \mathrm{s}$. Since the NTH3 is of the lowest times of startup (2404), escalation of the boundary will case less reduction in times of startup. Consequently, the reduction in power production per startup in NTH3 is much faster than that of other sites.

\section{Interannual variation of wind condition}

Since wind condition could have notable impact on the times of startup, the interannual variation of wind and its impact on uncertainty of effect of dead band are investigated in this section.

Table 5. Annual mean wind speed of consecutive 5 years $(\mathrm{m} / \mathrm{s})$

\begin{tabular}{ccccccccccccccccc}
\hline Time span & STH1 & STH2 & STH3 & CTY1 & CKS1 & CKS2 & CKS3 & MWT1 & MWT2 & MWT3 & CNI1 & CNI2 NTH1 NTH2 NTH3 \\
\hline $03-04$ & 10.37 & 9.70 & 11.23 & 8.56 & 9.31 & 11.48 & 11.72 & 10.75 & 10.01 & 9.78 & 9.44 & 8.56 & 8.42 & 8.41 & 8.84 \\
$04-05$ & 10.22 & 9.79 & 11.52 & 8.03 & 8.88 & 10.82 & 11.17 & 10.76 & 9.970 & 9.62 & 9.12 & 8.83 & 8.50 & 8.24 & 8.74 \\
$05-06$ & 9.76 & 9.18 & 10.99 & 8.03 & 8.85 & 10.49 & 10.99 & 10.28 & 9.77 & 9.35 & 8.92 & 8.29 & 8.27 & 8.18 & 8.44 \\
$06-07$ & 10.46 & 10.21 & 12.24 & 8.61 & 9.27 & 11.05 & 11.46 & 10.82 & 10.44 & 9.59 & 9.31 & 8.76 & 8.60 & 8.36 & 8.72 \\
$07-08$ & 9.58 & 8.92 & 11.09 & 8.17 & 9.20 & 10.61 & 11.17 & 10.02 & 9.39 & 9.52 & 8.97 & 7.99 & 8.47 & 8.47 & 8.90 \\
$\begin{array}{c}\text { mean wind } \\
\text { 10.08 }\end{array}$ & 9.56 & 11.41 & 8.28 & 9.10 & 10.89 & 11.3 & 10.53 & 9.91 & 9.57 & 9.15 & 8.49 & 8.45 & 8.33 & 8.73 \\
$\begin{array}{c}\text { standard } \\
\text { deviation }\end{array}$ & 0.39 & 0.51 & 0.50 & 0.28 & 0.22 & 0.39 & 0.29 & 0.36 & 0.38 & 0.16 & 0.22 & 0.35 & 0.12 & 0.12 & 0.18 \\
$\begin{array}{c}\text { Coefficient } \\
\text { of variation }\end{array}$ & 3.84 & 5.32 & 4.39 & 3.43 & 2.43 & 3.62 & 2.54 & 3.39 & 3.86 & 1.64 & 2.40 & 4.06 & 1.46 & 1.44 & 2.04 \\
\begin{tabular}{c} 
(\%) \\
\hline
\end{tabular} & & & & & & & & & & & & & & \\
\hline
\end{tabular}

Table 6. Annual times of startup of consecutive 5 years

\begin{tabular}{|c|c|c|c|c|c|c|c|c|c|c|c|c|c|c|c|c|c|c|c|c|}
\hline 常 & $\begin{array}{l}\text { boundary } \\
(\mathrm{m} / \mathrm{s})\end{array}$ & $\begin{array}{c}03- \\
04 \\
\end{array}$ & $\begin{array}{c}04- \\
05 \\
\end{array}$ & $\begin{array}{c}05- \\
06 \\
\end{array}$ & $\begin{array}{c}06- \\
07 \\
\end{array}$ & $\begin{array}{c}07- \\
08 \\
\end{array}$ & 常 & $\begin{array}{l}\text { boundary } \\
(\mathrm{m} / \mathrm{s})\end{array}$ & $\begin{array}{c}03- \\
04 \\
\end{array}$ & $\begin{array}{c}04- \\
05 \\
\end{array}$ & $\begin{array}{c}05- \\
06 \\
\end{array}$ & $\begin{array}{c}06- \\
07 \\
\end{array}$ & $\begin{array}{c}07- \\
08 \\
\end{array}$ & $=$ & $\begin{array}{c}\text { oundary } \\
(\mathrm{m} / \mathrm{s})\end{array}$ & $\begin{array}{r}03- \\
04 \\
\end{array}$ & $\begin{array}{c}04- \\
05 \\
\end{array}$ & $\begin{array}{c}05- \\
06 \\
\end{array}$ & $\begin{array}{c}06- \\
07 \\
\end{array}$ & $\begin{array}{c}07- \\
08 \\
\end{array}$ \\
\hline & 3.0 & 828 & 894 & 1017 & 960 & 1015 & & 3.0 & 342 & 443 & 489 & 435 & 455 & \multirow{3}{*}{ Z } & & 708 & 659 & 747 & 716 & 770 \\
\hline & 3.5 & $72 \%$ & $72 \%$ & $70 \%$ & $69 \%$ & $70 \%$ & $U_{2}$ & 3.5 & $66 \%$ & $63 \%$ & $62 \%$ & $66 \%$ & $63 \%$ & & 3.5 & $66 \%$ & $66 \%$ & $67 \%$ & $67 \%$ & $62 \%$ \\
\hline & 4.0 & $57 \%$ & $56 \%$ & $52 \%$ & $54 \%$ & $56 \%$ & & 4.0 & $53 \%$ & $51 \%$ & $46 \%$ & $49 \%$ & $49 \%$ & & 4.0 & $50 \%$ & $50 \%$ & $50 \%$ & $47 \%$ & $48 \%$ \\
\hline \multirow{3}{*}{ E } & & 559 & 543 & 650 & 523 & 691 & & & 418 & 476 & 494 & 454 & 477 & \multirow{3}{*}{$\sum_{i}$} & & 35 & 499 & 591 & 534 & 715 \\
\hline & 3.5 & $68 \%$ & $70 \%$ & $70 \%$ & $69 \%$ & $69 \%$ & $\approx$ & 3.5 & $82 \%$ & $81 \%$ & $82 \%$ & $78 \%$ & $83 \%$ & & J & $64 \%$ & $63 \%$ & $64 \%$ & $66 \%$ & $66 \%$ \\
\hline & 4.0 & $51 \%$ & $52 \%$ & $52 \%$ & $54 \%$ & $54 \%$ & & 4.0 & $70 \%$ & $70 \%$ & $70 \%$ & $66 \%$ & $69 \%$ & & 4.0 & $46 \%$ & $46 \%$ & $48 \%$ & $49 \%$ & $47 \%$ \\
\hline \multirow{3}{*}{ Es } & 3.0 & 462 & 434 & 522 & 464 & 553 & & 3.0 & 474 & 431 & 430 & 421 & 427 & \multirow{3}{*}{ L } & 3.0 & 566 & 576 & 565 & 518 & 595 \\
\hline & 3.5 & $72 \%$ & $68 \%$ & $71 \%$ & $72 \%$ & $72 \%$ & & 3.5 & $57 \%$ & $64 \%$ & $63 \%$ & $62 \%$ & $66 \%$ & & 3.5 & $64 \%$ & $65 \%$ & $64 \%$ & $68 \%$ & $63 \%$ \\
\hline & 4.0 & $57 \%$ & $54 \%$ & $55 \%$ & $54 \%$ & $53 \%$ & $\Sigma$ & 4.0 & $43 \%$ & $47 \%$ & $50 \%$ & $48 \%$ & $52 \%$ & & 4.0 & $50 \%$ & $47 \%$ & $47 \%$ & $53 \%$ & $47 \%$ \\
\hline \multirow{3}{*}{ 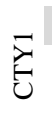 } & 3.0 & 716 & 808 & 837 & 709 & 770 & & 3.0 & 558 & 564 & 460 & 528 & 614 & \multirow{3}{*}{ I } & 3.0 & 447 & 439 & 536 & 417 & 429 \\
\hline & 3.5 & $69 \%$ & $70 \%$ & $67 \%$ & $67 \%$ & $66 \%$ & & 3.5 & $64 \%$ & $62 \%$ & $65 \%$ & $63 \%$ & $63 \%$ & & 3.5 & $68 \%$ & $64 \%$ & $67 \%$ & $62 \%$ & $64 \%$ \\
\hline & 4.0 & $52 \%$ & $56 \%$ & $52 \%$ & $50 \%$ & $49 \%$ & 5 & 4.0 & $47 \%$ & $43 \%$ & $50 \%$ & $45 \%$ & $45 \%$ & & 4.0 & $46 \%$ & $47 \%$ & $46 \%$ & $46 \%$ & $48 \%$ \\
\hline \multirow{3}{*}{ Un } & 3. & 606 & 699 & 780 & 656 & 663 & & 3.0 & 443 & 428 & 471 & 498 & 456 & \multirow{3}{*}{$\frac{T}{E}$} & 3.0 & 452 & 446 & 553 & 498 & 437 \\
\hline & 3 & $76 \%$ & $75 \%$ & $71 \%$ & $76 \%$ & $73 \%$ & & 3.5 & $73 \%$ & $71 \%$ & $74 \%$ & $70 \%$ & $74 \%$ & & 3.5 & $71 \%$ & $72 \%$ & $68 \%$ & $73 \%$ & $73 \%$ \\
\hline & 4.0 & $59 \%$ & $62 \%$ & $58 \%$ & $61 \%$ & $60 \%$ & & 4.0 & $56 \%$ & $57 \%$ & $57 \%$ & $58 \%$ & $59 \%$ & & 4.0 & $58 \%$ & $55 \%$ & $55 \%$ & $53 \%$ & $58 \%$ \\
\hline
\end{tabular}

The annual mean wind speed, its standard deviation, and coefficient of variation in each site of the consecutive 5 years from 2003 to 2008 are calculated and listed as Table 5. It can be observed that standard deviations in majority of sites (except STH2 and STH3) range between 0.12 to 0.40 and their coefficient of variation of annual mean 
wind speed ranges between $1.4 \%$ to $4.0 \%$, which suggest there is moderate interannual variability in majority of sites.

In order to analyze the uncertainty in the effect of dead band under the context of interannual variability of wind conditions, annual times of startup without dead band are listed as Table 6. In order to provide with an explicit view, the annual times of startup with an upper boundary of $3.5 \mathrm{~m} / \mathrm{s}$ and $4.0 \mathrm{~m} / \mathrm{s}$ are divided by that without dead band and listed in Table 6, too.

It can be observed that there are rather small interannual variations in percentage of annual times of startup with dead band to that without dead band. The interannual variations in percentage of majority of sites are less than 5\%, while the largest variation, $10 \%$, occurs in MWT1 with boundary of $3.5 \mathrm{~m} / \mathrm{s}$ (57\% in $2003-2004$ and $66 \%$ in 20072008 ) and $4.0 \mathrm{~m} / \mathrm{s}$ (43\% in 2003-2004 and 52\% in 2007-2008). Therefore, it is speculated that the dead band determined based on historical data could achieve similar performance in reducing unnecessary startup in the coming days.

\section{Conclusions}

Startup speed with dead band is proposed in the article to prevent frequent startup \& shutdown of wind turbines.

- Analysis of wind data of 15 actual and potential wind farms indicates that there is notable difference in the times of startup in different sits. The difference in times of startup is of no relation to the mean wind speed. It is speculated that the difference is caused by the local terrain related wind condition, such as turbulence.

- Numerical simulation suggests that the times of startup with an upper boundary of $4.0 \mathrm{~m} / \mathrm{s}$ could be reduced to below $50 \%$ of original number in majority of sites. The reduction in times of startup ranges from 729 to 2176 in the investigated 5 years.

- The reduction in wind power generation ranges from $1545 \mathrm{kWh}$ to $4308 \mathrm{kWh}$ with upper boundary of $4.0 \mathrm{~m} / \mathrm{s}$ during the whole 5 years. Although the benefit brought by reduction in times of startup cannot be quantified yet, the dead band of $4.0 \mathrm{~m} / \mathrm{s}$ is acceptable since associated loss is trivial.

- Although there are moderate interannual variability in the wind condition, performance of dead band remains stable. Therefore, it is reasonable to determine an appropriate configuration of dead band based on statistical analysis of historical wind data.

Acknowledgements. The authors would like to thank Wuhan University for providing the resources and facilities. Funding support of Hunan education department grant of 14k002, 15A005, and 2014ZNDL003 and Hunan Natural Science Foundation 2016WK2016, and Natural Science Foundation of China 61233008,51507014 are greatly appreciated.

\section{REFERENCES}

[1] Anthonis, J., Seuret, A., Richard, J. P., Ramon, H. (2007): Design of a pressure control system with dead band and time delay. - IEEE Trans Cont. Syst. Tech. 15(6): 1103-1111.

[2] Ashcroft, J. (1994): The relationship between the gust ratio, terrain roughness, gust duration and the hourly mean wind speed. - Journal of Wind Engineering and Industrial Aerodynamics 53(3): 331-355.

[3] Choi, J. H., Moon, S. I. (2009): The dead band control of LTC transformer at distribution substation. - IEEE Trans Power Syst. 24(1): 319-326. 
[4] Power curve of Vestas. [Online] Available: https://inlportal.inl.gov/portal/ server.pt/community/wind_power/424/software, Accessed: 2008

[5] Ribrant, J., Bertling, L. M. (2007): Survey of failures in wind power systems with focus on swedish wind power plants during 1997-2005. - IEEE Trans. Energy Conversion 22(1): 167-173.

[6] Turner, R., Tait, A., Uddstrom, M., Moore, S., Carey-Smith, T. (2009): Generating synthetic wind data. Available Online: http://www.niwa.co.nz/ environmentalinformation/research-projects/synthetic-wind-data.

[7] Walford, C. (2006): Wind turbine reliability: understanding and minimizing wind turbine operation and maintenance costs. - Sandia National Laboratories, Rep. SAND-2006-1100.

[8] WS Scientific Inc. \& National Renewable Energy Laboratory (U.S.) (1997): Wind Resource Assessment Handbook. - fundamentals for conducting a successful monitoring program. (CESTM, Albany, NY).

[9] Wu, X. Li, Y. Y., Li, F., Yang, Z. Z., Teng, W. (2012): Adaptive estimation-based leakage detection for a wind turbine hydraulic pitching system. - IEEE/ASME Trans. Mechatronics 17(5): 907-914.

[10] Yampikulsakul, N., Byon, E., Huang, S., Sheng, S., You, M. (2014): Condition monitoring of wind power system with nonparametric regression analysi. - IEEE Trans. Energy Conversion 29(2). 